\title{
DETC05/DTM-00000
}

\section{AN ANALYSIS OF RISK AND FUNCTION INFORMATION IN EARLY STAGE DESIGN}

\author{
Katie Grantham, Michael Van Wie, Robert Stone \\ University of Missouri-Rolla \\ kag@umr.edu,vanwie@umr.edu, rstone@umr.edu
}

\author{
Francesca Barrientos, Irem Tumer \\ NASA-Ames Research Center \\ fbarrientos@mail.arc.nasa.gov, itumer@mail.arc.nasa.gov
}

\begin{abstract}
The concept of function offers a high potential for thinking and reasoning about designs as well as providing a common thread for relating together other design information. This paper focuses specifically on the relation between function and risk by examining how this information is addressed for a design team conducting early stage design for space missions. Risk information is decomposed into a set of key attributes which are then used to scrutinize the risk information using three approaches from the pragmatics sub-field of linguistics: i) Gricean, ii) Relevance Theory, and Functional Analysis. Results of this linguistics-based approach descriptively account for the context of designer communication with respect to function and risk, and offer prescriptive guidelines for improving designer communinication.
\end{abstract}

\subsection{INTRODUCTION}

Risk information is an important component throughout all stages of the design process that allows engineers to make informed decisions. Identifying, communicating with, and acting on risk information are difficult tasks given the uncertainty and incompleteness inherent in design. Various processes such as Failure Modes and Effects Analysis and Process Hazard Analysis are used in industry to elicit risks and provide a standard framework on which discussion of risk can take place. In general, the goal is to ultimately describe a risk in terms of likelihood and consequence regarding a particular failure event. Reaching this goal is challenging especially in early design stages when physical solutions have not yet been selected and the design is described mainly in functional terms.

Functional descriptions are form independent specifications of design solutions that offer convenience for early stage design when generally many physical solutions have neither been chosen or ruled out. While many function based approaches have been proposed including IDEF models (NIST, 1993) and the functional basis (Hirtz et al., 2002), usage and adoption of functional modeling tools in engineering practice is mixed with little consensus as to an industry wide functional modeling standard for mechanical systems. By comparison, the Unified Modeling Language (UML) for software systems is a well-refined standard and widely used. Instead, early stage design may simply utilize terminology evolved in industry and references to physical solutions to support discourse and initial system modeling. Understanding the relation between this type of terminology and more formal functional languages, such as the functional basis, is important because this relation allows associations to be drawn between actual design language and many types of design information, including risk. This sets the stage to explore new design methods that associate risk and failure information with functional-like descriptions that occur during natural discourse in engineering design settings.

For this paper, we address risk and function information with regard to an early stage design team at the Jet Propulsion Laboratory known as Team $\mathrm{X}$. We examine how this team treats risks through analysis of excerpt samples and related data from past Team $X$ design reports. This team performs conceptual design for space missions and is a good model for studying design activity given the multi disciplinary team makeup and the variety of missions involved.

The purpose of this work is to better understand risk and function information as communicated in the Team $X$ setting. A brief outline of the paper, as the approach section will detail, begins with decomposing risk information into meaningful categories. This provides a direct result of risk composition and provides a means for analyzing, according to these categories, the risk data from a linguistic perspective that directly accounts for communication effects. Finally, we present a set of functional templates that map between physical solution descriptions, as referenced in Team $\mathrm{X}$ terminology, to functions in the functional basis. These templates provide a link between the natural language in a design setting to more formal terminology that can then be used in function based 
methods such as the Function Failure Design Method (Tumer et al., 2002).

\subsection{BACKGROUND}

The primary articles of interest for this work are risk elements, defined broadly here as phrases describing a failure, a failure scenario, failure cause, failure effect, an issue to consider related to a failure, or a concern related to a failure. Risk elements are isolated pieces of data from Team X sessions that are the focus of this work.

Risk elements are elicited, discussed, and documented during Team X design sessions. Team X consists of about 19 members, in a war room type setting to produce conceptual designs of space missions (Mark, 2002). One team member is tasked with compilation of all risk elements for a given design. This involves proactive participation with other team members to adequately identify risks. Each risk is recorded in a 2-D fever chart with axes of likelihood and consequence of failure. Certain failures warrant the generation of mitigations to reduce the risk. Risk elements and any mitigations are listed in design session results in addition to being used in certain risk support tools undergoing continual development such as the Risk Analysis Prototy pe (RAP) tool (Meshkat et al., 2003).

Part of the interest in investigating risk and function information during Team $\mathrm{X}$ designs stems from recent work in formalizing functions (Hirtz et al., 2002) and failure modes (Tumer et al., 2003). At present there is also an established relationship between product function and failure modes. This relationship is dependent on the languages used to describe both function and failure (Stone et al., 2005; Tumer and Stone, 2002; Uder et al., 2004). It is desirable to extend this mapping to risk assessment and this work uses concepts from linguistics to study risk and function information.

In the area of linguistics, the sub-field of pragmatics deals specifically with the issues of how utterances or statements are used in communicative acts and how those statements are related to the context in which they are spoken (Barsalou, 1992; Ward, 19XX; Wilson, 1999). Understanding how people produce and comprehend utterances as they relate to a given context encapsulates much of the knowledge we seek toward explaining how designers communicate with risk and how they perhaps should communicate with risk information during conceptual design. The following three sections give a snapshot of three somewhat competing theories of pragmatics.

\subsection{Gricean Cooperation Principle}

The Gricean approach is perhaps the most often cited approach and rests on the Gricean Cooperation Principle. This principle consists of 4 maxims that are related to cooperative interaction (Barsalou, 1992). The maxims are as follows:

Quantity: Utterances should be as informative as possible but not more informative than required.

Relevance: Utterances should be relevant to the goals of the current conversation.

Quality: Utterances should be true and based on sound evidence.

Manner: Utterances should be clear, unambiguous, and orderly.
According to this principle, unless the goal of communicators is deceit, the 4 maxims should be followed for the communication to be effective. Therefore, statements of risk element should follow all the maxims.

\subsection{Functional Approach}

The functional approach of pragmatics suggests that there are seven different functions that can be performed with communication. These functions are instrumental, regulatory, interaction, personal, imaginative, heuristic, and informative. The latter is the most relevant to analyzing risks. Communication is said to be informative when the language is used to convey information to other people about things not visible in the immediate environment.

For the purposes of this analysis, it is deemed that statements of risk should primarily perform the informative function of communication.

\subsection{Relevance Theory}

The relevance theory of pragmatics is composed of two parts, positive cognitive effect, and processing effort.

1. Other things being equal, the greater the positive cognitive effects achieved by processing an input, the greater the relevance of the input to the individual at that time.

2. Other things being equal, the greater the processing effort expanded, the lower the relevance of the input to the individual at that time.

\subsection{Background Summary and Motivation}

The above concepts from linguistics provides a theoretical basis for analyzing risk data from Team $\mathrm{X}$ design sessions and prescribing corrective actions to improve communication regarding risk and function information. One premise for this research is that communication among designers can be improved regarding notions of both function and risk by addressing the established concepts of pragmatics. In particular, we isolate the language of designers, albeit through written reports, as the article under examination where we apply basic concepts of linguistic analysis to scrutinize current design communication practices. The expectation is that our conclusions i) will have a positive influence on how Team $\mathrm{X}$ and similar teams perform their work ii) will help design researchers understand certain characteristics of design language in general and iii) will expose how a linguistic perspective can offer insight into research on designer communication.

\subsection{OBJECTIVES}

The overall goal of this work is to analyze risk and function content of designer communication in order to understand the current deficiencies of risk statements and propose a systematic, function based approach to risk assessment. Toward this goal, our objectives are to:

- establish a set of attributes for risk elements,

- evaluate the risk elements in light of these attributes and the three approaches from pragmatics, 
- $\quad$ propose corrective steps to better address risk.

\subsection{APPROACH}

\subsection{Identifying Risk Element Attributes}

Here we develop a set of attributes for risk elements. Specific examples of risk elements are given next to understand the nature of risk elements.

\subsubsection{Risk Element Examples}

The following risk elements illustrate the heterogeneous nature of the data within a risk element. The following highlights three risk elements to show the nature of risk element language and information content. Given the lack of specificity for some risk elements, it is difficult in these cases to associate a narrow set of functionality with the risk element. For example, the risk of an inaccurate landing is associated with a great number of functions.

\section{Example risk element \#1: "Instruments not able to view} sample"

In this case it is clear that the performance parameter is "view sample accurately," but there is no hint of exactly what is causing the failure.

Example risk element \#2: "Insufficient performance" This risk element is not very informative.

\section{Example risk element \#3: "Insufficient power for drilling} operations"

This risk element is somewhat ambiguous because it is not clear if the power source is the problem or if a downstream system, for whatever reason, requires more than the specified nominal or peak power than this downstream system should.

Example risk element \#4: "Grounding faults during pyros"

This risk element is clear in description of an event, but does not clearly indicate much regarding the context of the event.

\subsubsection{Risk Element Attributes}

Variations in terminology associated with risks are apparent when considering different government organizations and industry groups including DOD, NASA and ISO based standards. The few examples above suggest that significant variations exist within documented risks of Team $X$ in terms of the information content. In order to analyze these risks, we first consider terminology associated with risks from multiple standards and practices as listed in Table 1.

Table 1. Sample Sources for Risk Terminology

\begin{tabular}{|l|}
\hline Department of Defense \\
\hline NASA - JPL Risk Management \\
\hline NASA NPG 7120.5B (Program and Project \\
Management Processes and Requirements) \\
\hline Risk Assessment Prototype (RAP risk tool used at JPL) \\
\hline Space Systems Risk Assessment (ISO 17666) \\
\hline Det Norske Veritas (DNV) Risk Consultants \\
\hline Probablistic Risk Analysis \\
\hline
\end{tabular}

A brief review of information from the sources in Table 1 indicates that there are many types or categories of risk. Some examples from ISO 17666 include "risk index, risk trend, residual risk, risk scenario," etc. However, these sources also reveal a reasonable consensus on the basic notion of risk in which a likelihood and consequence of failure is accounted. As noted at the beginning of section 4.1 , we take a somewhat broad view of risk elements where we account for several categories of risk knowing that ultimately much of risk information is distilled into basic quantities such as likelihood and consequences.

Given this rather inclusive perspective for risk elements, we define five attributes to describe risk element attributes. Additional attributes can be defined such as likelihood of failure although these five attributes are suitable for studying the information found in risk element titles and descriptions, which are the primary documented source of how Team $\mathrm{X}$ designers communicate with risk information.

For a portion of the risk elements provided (17 earth orbit elements and 100 of the moon mission risk elements), each of the risk element attributes shown in Table 2 are identified. Due to the vagueness of some risk elements, values are not assigned to all attributes for the 117 risk elements inspected.

The attributes are defined in Table 2 and an example of these attributes is given in Table 3 for the risk element titled "Vibration Damage to Telescope" with a description of "Not obvious that telescope assemblies will survive launch profile" and reference to the "Science" and "Instrument" subsystems. The values for each attribute are inferred from the risk element title, description and the referenced subsystems. Note that in our analysis, we only address functionality for the design parameters although one may reasonably also consider other system specifications such as geometric or material choices. This restriction allows a direct account of function information present in risk elements.

\section{Table 2. Risk Element Attribute Definitions}

\begin{tabular}{|l|l|}
\hline Attribute & Definition \\
\hline $\begin{array}{l}\text { Performance } \\
\text { Parameter }(P)\end{array}$ & $\begin{array}{l}\text { Measurable indicator of system performance with } \\
\text { respect to design objectives }\end{array}$ \\
\hline $\begin{array}{l}\text { Design } \\
\text { Parameters }(D)\end{array}$ & $\begin{array}{l}\text { Parameters of a system which can be specified within } \\
\text { the scope of the design }\end{array}$ \\
\hline $\begin{array}{l}\text { Noise } \\
\text { Parameter }(N)\end{array}$ & $\begin{array}{l}\text { Parameters of the system or system operation that are } \\
\text { beyond the control of the designer }\end{array}$ \\
\hline $\begin{array}{l}\text { Failure Mode } \\
(F M)\end{array}$ & $\begin{array}{l}\text { A specific event that prevents proper functioning of a } \\
\text { system }\end{array}$ \\
\hline $\begin{array}{l}\text { Failure Scenario } \\
(F S)\end{array}$ & $\begin{array}{l}\text { A sequence of events and their context that results in } \\
\text { one or more Failure Modes }\end{array}$ \\
\hline
\end{tabular}

Table 3. Example Risk Element Attributes

\begin{tabular}{|l|l|}
\hline Attribute & Examples \\
\hline$(P)$ & Optical performance parameters for telescope \\
\hline$(D)$ & $\begin{array}{l}\text { Primary function - "channel, signal, control magnitude" } \\
\text { Secondary function - "import, export, sense, process, } \\
\text { actuate, regulate, change, stop" }\end{array}$ \\
\hline$(N)$ & Vibration loading due to launch \\
\hline$(F M)$ & Fatigue, structural failure \\
\hline$(F S)$ & $\begin{array}{l}\text { Vibration during launch leading to fatigue, structural } \\
\text { failure of the telescope assembly }\end{array}$ \\
\hline
\end{tabular}




\subsection{Pragmatics Analysis}

The approach is to use a basic set of concepts from pragmatics, which is a sub-field of linguistics, to analyze the sample of 117 risk elements. We examine Team X communication from three perspectives found in pragmatic literature as described in the section 2: Gricean, Relevance Theory, and a Functional approach. The approach to analyze the risk elements consists of four steps.

Step 1: Relate each linguistic theory to the risk elements. Each linguistic theory is written relating to conversation in general, this step transforms the generality of the statement to one that pertains to risk elements.

Step 2: Derive specific questions to relate the linguistic theories to risk element attributes. These questions transition the general statements about risk achieved from Step 1 into specific questions about risk element properties. Answering these specific risk element property questions aims at validating (or invalidating) the general risk statement from Step 1 and thus the linguistic theory.

Step 3: Derive logical relationships for the risk element attributes to determine if the linguistic theory criteria is satisfied. The relationships between the risk element attributes and the linguistic theories determined in Step 2 are translated into logical relations in this step. A true result from the logical statement implies that the linguistic theory has been satisfied.

Step 4: Evaluate each risk element. The set of risk elements under evaluation are first examined with respect to their risk attribute makeup. Then the risk element attribute makeup is entered into the logical relationships from Step 43 and analyzed.

The data used to analyze the risk elements is identified for the Gricean Cooperation Principle, Functional Approach and the Relevance Theory in Tables 4, 5, and 6 respectively. The various linguistic theories and theory specific risk element relations are described in the following sections.

\subsubsection{Gricean Cooperation Principle}

The Gricean Cooperation Principle is used in this section to analyze the risk elements with respect to pragmatics. Recalling the four maxims, the first maxim involves quantity. It was determined that a risk element that contains information about a design parameter and a failure mode had presented the minimum quantity of information about the risk element. These two attributes were singled out because they identify the problem (failure mode) and its effect (design parameter). Also, to prevent providing too many risk elements, i.e. too much quantity, the two parameters coupled together should only appear once per risk analysis.

The next maxim is relevance. A risk element is deemed relevant if it contains any of the 5 risk element attributes this work is examining since the goal of the conversation is to gather information about potential risks.

The quality maxim is first concerned with the truth about the risk element and then the justification for the risk element. Therefore, the first part of the quality analysis involved checking to make sure the risk element is feasible. The second part of the quality analysis involves evidence that a particular failure mode could occur through past failures or supporting calculations.

The final Gricean maxim is manner. For the purposes of this analysis all the risk elements are assumed to be orderly. This leaves their clarity and unambiguousness to analyze. A risk element is deemed unambiguous if it contains information on the source of the problem (failure scenario, noise parameter) and the function it affects (design parameter). Furthermore, a risk element is deemed clear if it contains information on the affected performance (performance parameter), and what is causing the problem (failure mode).

\subsubsection{Functional Approach}

Since the risk elements themselves are shared with others and the risk element attributes are invisible; yet desirable, information, the risk elements are deemed informative if they contain information regarding at least one of the risk element attributes.

\subsubsection{Relevance Theory}

The proposition dealing with positive cognitive effect was related to the risk elements by counting the risk element attributes of a risk element. The greater the number of attributes in a risk element has the more the positive cognitive effect because it has adequately described the risk. The second proposition of which relates to processing effort was divided into two categories, nominal processing and too much processing. The risk elements require nominal processing if they contain between 3 and 5 of the risk element attributes. If there are less than 3 or more information that the risk element attributes then the risk element requires too much processing, which, in turn, lowers the relevance of the risk item. 
Table 4: Risk Element Categories of Gricean Cooperation

\begin{tabular}{|c|c|c|c|c|c|c|}
\hline Maxim & Description & Risk Questions & & & rty Specific Questions & Logical \\
\hline Quantity & $\begin{array}{l}\text { Utterances should be as } \\
\text { informative as possible but not } \\
\text { more informative than } \\
\text { required. }\end{array}$ & $\begin{array}{l}\text { Is the risk element } \\
\text { informative? } \\
\text { Is the risk element } \\
\text { efficiently } \\
\text { informative? }\end{array}$ & $\begin{array}{l}D \\
F M\end{array}$ & $\begin{array}{l}\text { Qn.1 } \\
\text { Qn.2 }\end{array}$ & $\begin{array}{l}\text { Does the risk element contain D } \\
\& \text { FM? } \\
\text { Does the specific D \& FM appear } \\
\text { only in this particular risk } \\
\text { elements? }\end{array}$ & $\begin{array}{l}\text { IF (D \& FM) Then } \\
\text { Qn. } 1=\text { True } \\
\text { If (D \& FM are } \\
\text { specific to the risk) } \\
\text { then Qn. } 2=\text { True }\end{array}$ \\
\hline Relevance & $\begin{array}{l}\text { Utterances should be relevant } \\
\text { to the goais of the current } \\
\text { conversation. }\end{array}$ & $\begin{array}{l}\text { Is the risk element } \\
\text { specific to the } \\
\text { particular mission or } \\
\text { spacecraft? }\end{array}$ & $\begin{array}{l}\mathrm{P} \\
\mathrm{D} \\
\mathrm{N} \\
\mathrm{FM} \\
\mathrm{FS} \\
\end{array}$ & $\mathrm{R}$ & $\begin{array}{l}\text { Does the risk element contain } \\
\text { P,D.N.FM, or FS? }\end{array}$ & $\begin{array}{l}\text { IF (P or } D \text { or } N \text { or } \\
F M \text { or } F S) \text { then } \\
R=\text { True }\end{array}$ \\
\hline Quality & $\begin{array}{l}\text { Utterances should be true and } \\
\text { based on sound evidence. }\end{array}$ & $\begin{array}{l}\text { Is the risk element } \\
\text { true? }\end{array}$ & $\begin{array}{l}\mathrm{P} \\
\mathrm{D} \\
\mathrm{N} \\
\mathrm{FM} \\
\mathrm{FS} \\
\end{array}$ & $\begin{array}{l}\text { Q.1.1 } \\
\text { Q.1.2 } \\
\text { Q.1.3 }\end{array}$ & $\begin{array}{l}\text { Can the FM affect the P? } \\
\text { Is the D related to the P? } \\
\text { Can the FM be caused by the FS } \\
\text { or N? }\end{array}$ & \\
\hline & & $\begin{array}{l}\text { Is the risk element } \\
\text { based on sound } \\
\text { evidence? }\end{array}$ & FM & $\begin{array}{l}\text { Q.2.1 } \\
\text { Q.2.2 }\end{array}$ & $\begin{array}{l}\text { Has the FM occurred previously? } \\
\text { Are there supporting calculations } \\
\text { for the FM? }\end{array}$ & \\
\hline Manner & $\begin{array}{l}\text { Utterances should be clear, } \\
\text { unambiguous, and orderly. }\end{array}$ & $\begin{array}{l}\text { Is the risk element } \\
\text { clear? }\end{array}$ & $\begin{array}{l}\mathrm{P} \\
\mathrm{FM} \\
\end{array}$ & M.1 & $\begin{array}{l}\text { Does the risk contain a } \mathrm{P} \text { and } \\
\text { FM? }\end{array}$ & $\begin{array}{l}\text { IF (P \& FM) } \\
\text { Then M. } 1=\text { True }\end{array}$ \\
\hline & & $\begin{array}{l}\text { Is the risk element } \\
\text { unambiguous? }\end{array}$ & $\begin{array}{l}\mathrm{D} \\
\mathrm{N} \\
\mathrm{FS}\end{array}$ & M.2 & $\begin{array}{l}\text { Does the risk contain a } \mathrm{D} \text { and ( } \mathrm{N} \\
\text { or FS)? }\end{array}$ & $\begin{array}{l}\text { IF }(D \&(N \text { or } F S)) \\
\text { Then M.2=True }\end{array}$ \\
\hline
\end{tabular}

Table 5: Risk Element Categories of Function Approach

\begin{tabular}{|c|c|c|c|c|c|c|}
\hline $\begin{array}{c}\text { Communication } \\
\text { Function }\end{array}$ & Description & Risk Questions & $\begin{array}{c}\text { Risk } \\
\text { Attributes } \\
\text { Concerned }\end{array}$ & & ty Specific Questions & $\begin{array}{c}\text { Logical } \\
\text { Relationships }\end{array}$ \\
\hline Informative & $\begin{array}{l}\text { Language is used to convey } \\
\text { information to other people } \\
\text { about things not visible in } \\
\text { the immediate environment. }\end{array}$ & $\begin{array}{l}\text { Does the risk } \\
\text { element convey } \\
\text { information about } \\
\text { mission risks? }\end{array}$ & $\begin{array}{l}\text { P } \\
D \\
N \\
\text { FM } \\
\text { FS }\end{array}$ & $\mathrm{F}$ & $\begin{array}{l}\text { Does the risk element contain a } \\
\text { location for a problem ( } P \text { or } D) \\
\text { and a potential cause of the } \\
\text { problem ( } N \text { or FM or FS)? }\end{array}$ & $\begin{array}{l}\text { IF }\{(P \text { or } D) \& \\
(N \text { or FM or FS) } \\
\text { Then } F=\text { True }\end{array}$ \\
\hline
\end{tabular}

Table 6: Risk Element Categories of Relevance Theory

\begin{tabular}{|c|c|c|c|c|c|c|}
\hline $\begin{array}{l}\text { Relevance- } \\
\text { Theory } \\
\text { Principle } \\
\end{array}$ & Description & Risk Questions & $\begin{array}{c}\text { Risk } \\
\text { Attributes } \\
\text { Concerned }\end{array}$ & \multicolumn{2}{|c|}{ Property Specific Questions } & $\begin{array}{l}\text { Logical } \\
\text { Relationships }\end{array}$ \\
\hline $\begin{array}{l}\text { Positive Cognitive } \\
\text { Effect }\end{array}$ & $\begin{array}{l}\text { Other things being equal, the } \\
\text { greater the positive cognitive } \\
\text { effects achieved by } \\
\text { processing an input, the } \\
\text { greater the relevance of the } \\
\text { input to the individual. }\end{array}$ & $\begin{array}{l}\text { How well does the } \\
\text { risk element add to } \\
\text { the knowledge about } \\
\text { potential concern for } \\
\text { the mission? }\end{array}$ & $\begin{array}{l}\text { P } \\
\text { D } \\
\text { N } \\
\text { FM } \\
\text { FS }\end{array}$ & RT.1 & $\begin{array}{l}\text { How many risk element } \\
\text { attributes does the risk element } \\
\text { contain? }\end{array}$ & $\begin{array}{l}\text { Count } \\
\text { (P,D,N,FM,FS) for } \\
\text { each risk element. }\end{array}$ \\
\hline Processing Effort & $\begin{array}{l}\text { Other things being equal, the } \\
\text { greater the processing effort } \\
\text { expanded, the lower the } \\
\text { relevance of the input to the } \\
\text { individual at that time. }\end{array}$ & $\begin{array}{l}\text { Does the risk } \\
\text { element provide } \\
\text { only enough } \\
\text { information to easily } \\
\text { comprehend the } \\
\text { mission risk? }\end{array}$ & $\begin{array}{l}\mathrm{P} \\
\mathrm{D} \\
\mathrm{N} \\
\mathrm{FM} \\
\mathrm{FS}\end{array}$ & RT.2 & $\begin{array}{l}\text { Does the risk element contain } \\
\text { too little risk property } \\
\text { information or extraneous } \\
\text { information? }\end{array}$ & $\begin{array}{l}\text { If } \quad \text { Count } \\
(\mathrm{P}, \mathrm{D}, \mathrm{N}, \mathrm{FM}, \mathrm{FS}) \geq 3, \\
\text { then RT.2 = True }\end{array}$ \\
\hline
\end{tabular}

\subsection{Functional Template Development}

In addition to analyzing the extent to which functionality is addressed in risk elements, another issue to consider is the broader problem of how functionality is addressed during Team $\mathrm{X}$ design sessions in general. Based on preliminary inspections of the risk element samples as well as on-site observations of Team X members during their design sessions, it is clear that Team $X$ members utilize a somewhat specialized set of terminology to refer to what would otherwise be known as functionality. References to physical artifacts are prominent when discussing system function. This can be interpreted as a very form-centric (noun based) perspective, which poses a challenge if the goal is to explicitly account for system function. For example, references to an antenna and related physical systems may dominate a discussion that from a more function-centric view might be focused on functions (verb based) such as transmit signal.

One potential avenue for improving the treatment of function and consequently the treatment of function within the context of risk in design, is the development of relations between the terminology found in the Team $X$ environment 
with a more formal set of function terms such as those in the functional basis (Hirtz et al., 2002). A key problem is addressing functionality involved with space related systems in a manner that is both reasonably minimal and comprehensive. This gives rise to the notion of a functional template that represents a broad set of systems associated with space missions.

Here we develop a set of functional templates that intended to represent the breakdown of space mission systems in general and show their relation with functions in the functional basis language. This breakdown is at a very high level as shown in the appendix. This decomposition is intended to capture a basic set of physical elements that comprise the generality of space missions. Many partitioning schemes are possible for making this decomposition and we identify four systems: ground systems, launch vehicle, spacecraft, and payload. Note that these are not intended to replace existing work breakdown structures or the basic structure of Team X. Instead these four systems are established as a very high level set of physical systems. Some of the elements in both work breakdown structures and members of Team $X$ have a scope that is substantially different than that of a singular physical system. The issue of cost is one example.

The templates are structured as functions versus physical systems where the cell elements are assigned with flows. Both the functions and the flows are from the functional basis (Hirtz et al., 2002) and both are given only for the primary and secondary levels. Notation for the flows is given at the beginning of the appendix. A brief assessment of these templates is discussed in the results section of 5.4 .

\subsection{RESULTS}

The sample of risk elements cover 4 mission types: earth orbit, solar orbit, moon, and Mars missions. Generally, the documented risk elements are highly variable in their level of specificity as indicated in the examples in Section 4.1.1. The analysis presented here indicated the particular ramifications of the variable specificity as it relates to how well the risk element is being communicated and therefore (potentially) how well it is understood.

\subsection{Gricean Cooperation Principle}

Each risk element was subjected to the logical relationships associated with each portion of the maxims listed in Table 1. If the logical result was true, then that portion of the risk specific maxim was satisfied. A score of all trues would imply the risk element to be cooperative, which according to Grice is the goal of pragmatic speech. The results of this analysis are displayed in Figures 1 and 2. These figures shows that the maxim

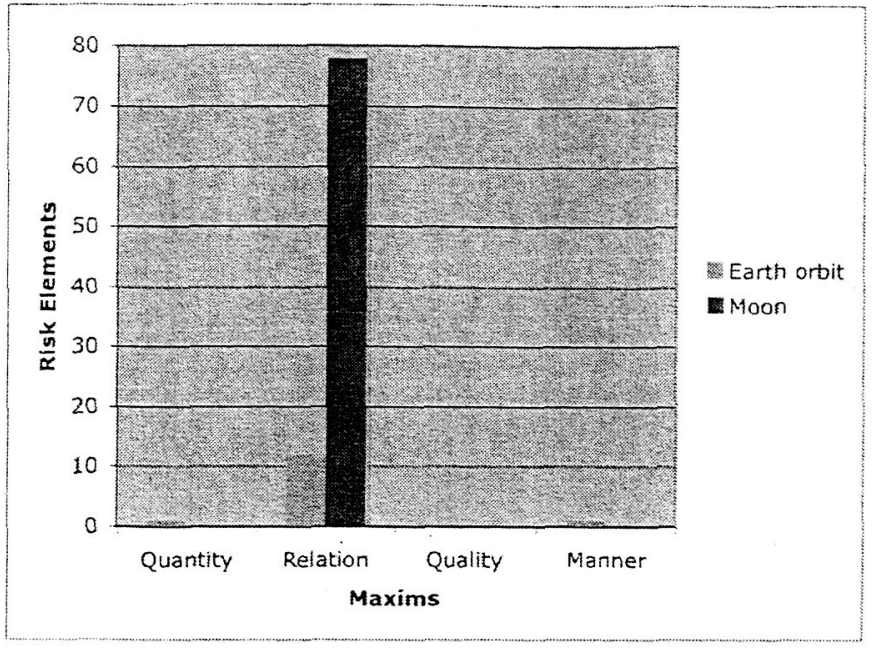

Figure 1: Gricean Risk Element Analysis

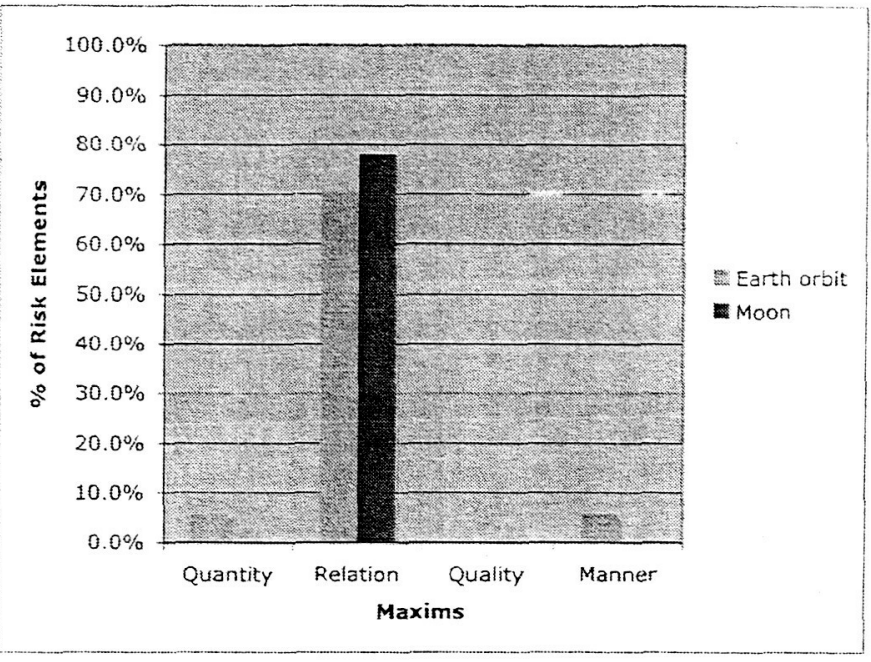

Figure 2: Griceañ Risk Element Añalysis - Percentage

satisfied by the most risk elements is relation. Quantity, Quality, and Manner are the least satisfied. A thorough examination of the results of each logical test for the least satisfied maxims provides insight as to the exact deficiencies.

The Quantity maxim results are shown in Figure 3. This figure depicts that the Earth orbit mission only had 1 risk element that satisfied the both of the requirements for quantity; therefore, the risk elements that satisfied the first portion of the quantity requirements had a design parameter and failure mode repeated in the other risk element which satisfied the first quantity requirement. Moreover, the moon mission did not have any risk elements which satisfied any portion of the quantity maxim. This is because there were no failure modes recorded in any of the Moon risk elements. 


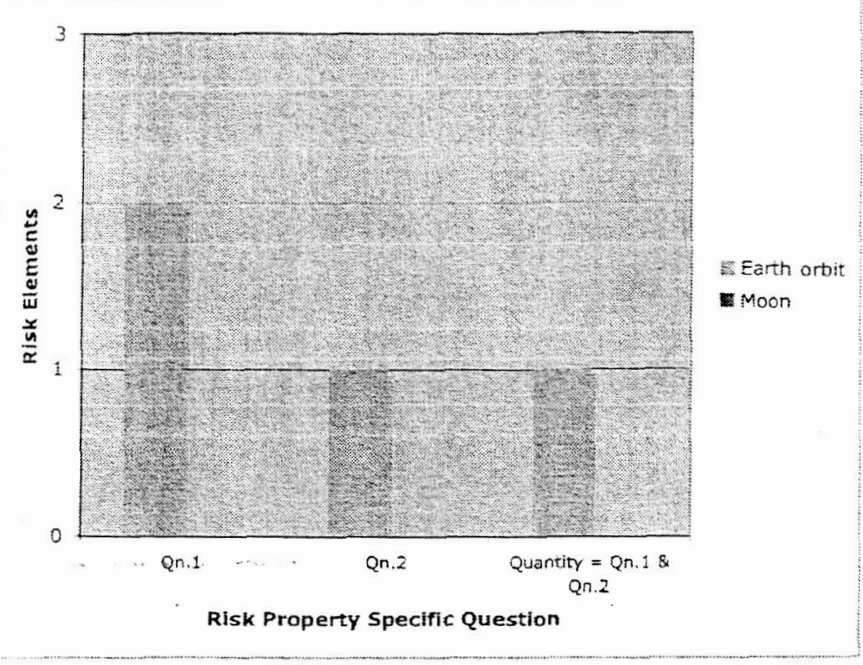

Figure 3: Gricean Risk Element Analysis - Quantity

The Quality Maxim is also deficient, according to Figure 1. A breakdown of the requirements for the quality maxim is shown in Figure 4. This figure demonstrates that the quality maxim had poor results due to requirements Q.1.3, Q.2.1, and Q.2.2 for the Moon mission and had poor Earth orbit results on all requirements except Q.1.2. As in the Quantity case, this is also due to lack of Failure Mode information.

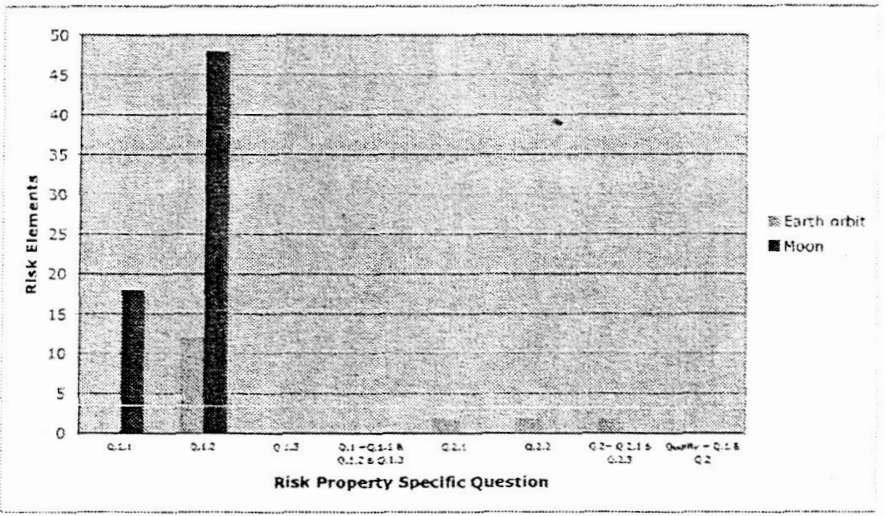

Figure 4: Gricean Risk Element Analysis - Quality

The last of the Gricean maxims is Manner and the breakdown of its results are shown in Figure 5. These results indicate that M.1 fails to satisfy the criteria in all but one case. This is again due to the lack of Failure Mode information. Also, M.2 is true more of the time; therefore, the risk elements tend to be unambiguous but are not totally clear with respect to performance parameters and failure modes. It appears that from these results the absence of failure mode data is preventing the risks from being clear. Interestingly many more are unambiguous (specific), despite being unclear.

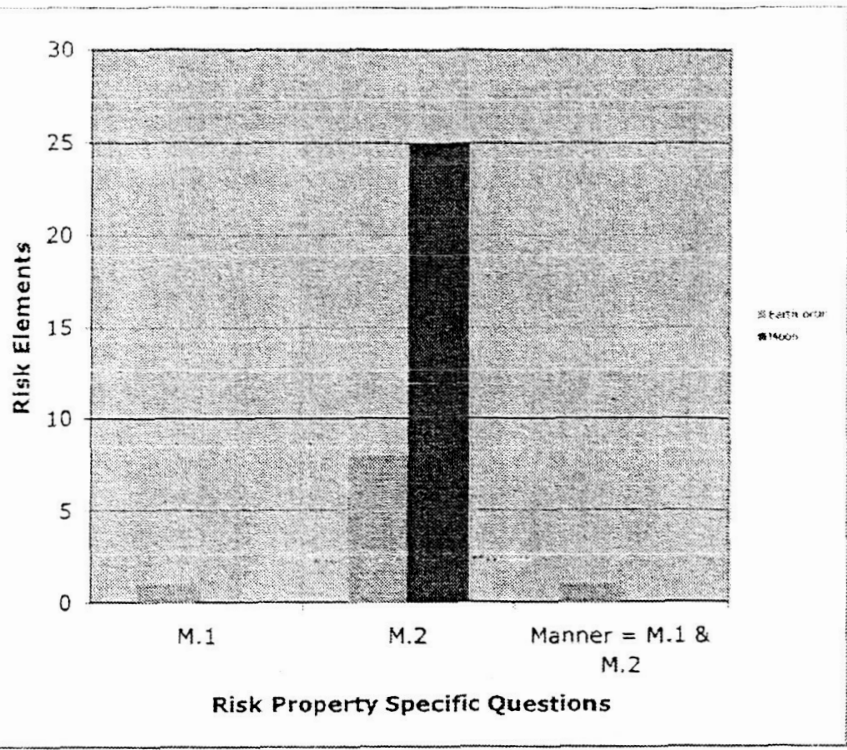

Figure 5: Gricean Risk Element Analysis - Manner

\subsection{Functional Approach}

As in the Gricean approach, each risk element was subjected to the logical relationships associated with each portion of the maxims listed in Table 2. If the logical result was true, then the risk element satisfied the requirement for the informative function of communication. The results from the Functional Approach are displayed in Figures 6 and 7. The results indicate that $47 \%$ of the Earth orbit and $30 \%$ of the Moon risk elements satisfy the informative communication function. These risk elements present a location for a problem (performance or design parameter )and a potential source (noise parameter, failure mode, or failure scenario) of the problem.

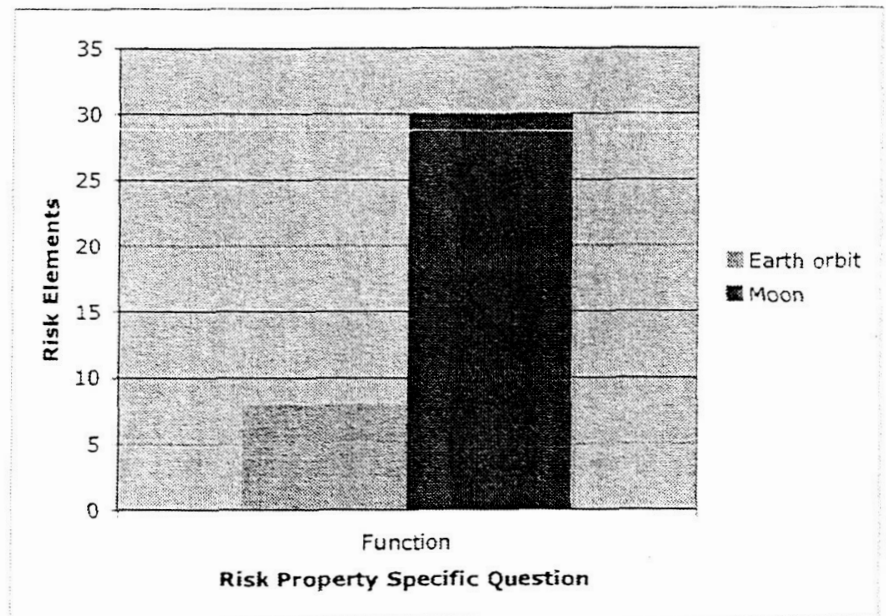

Figure 6: Function Risk Element Analysis 


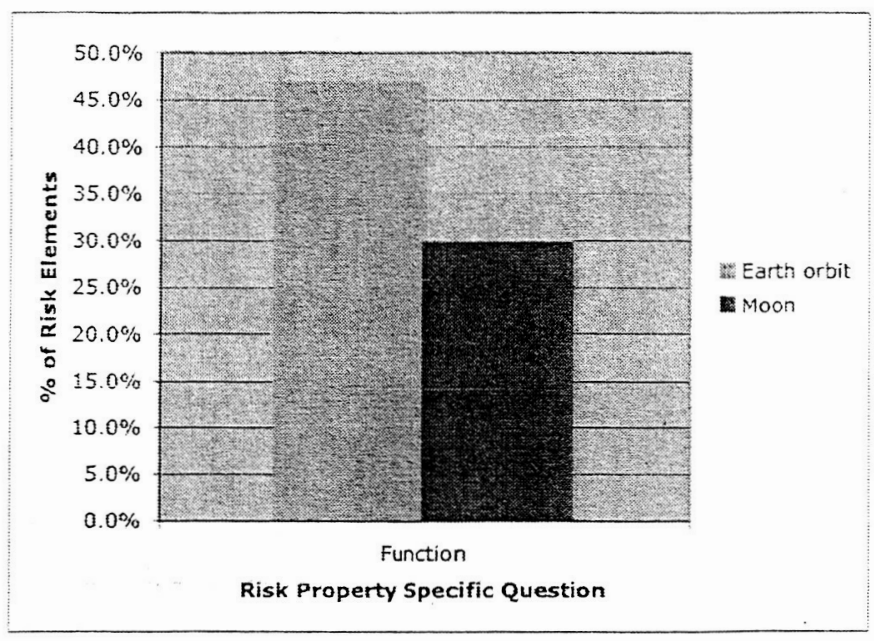

Figure 7: Function Risk Element Analysis-Percentage

\subsection{Relevance Theory}

The relevance theory resuits differ slightiy from the Gricean and Functional Approach results in that there is a count of the risk elements which separates the level of positive cognitive effect (or degree of satisfaction of RT.1) rather than a logical relationship. This portion of the relevance theory is concerned with maximizing positive cognitive effect; thereíore, the results presented here demonstrate the various levels of positive cognitive effect (which is greater for a risk element which is described by the most risk element attributes) demonstrated by the risk elements, see Figures 8 and 9 . Of the Earth orbit mission risk elements, $35 \%$ have at least 4 of the 5 risk element attributes. However, the Moon mission risk elements have at maximum 3 risk element attributes.

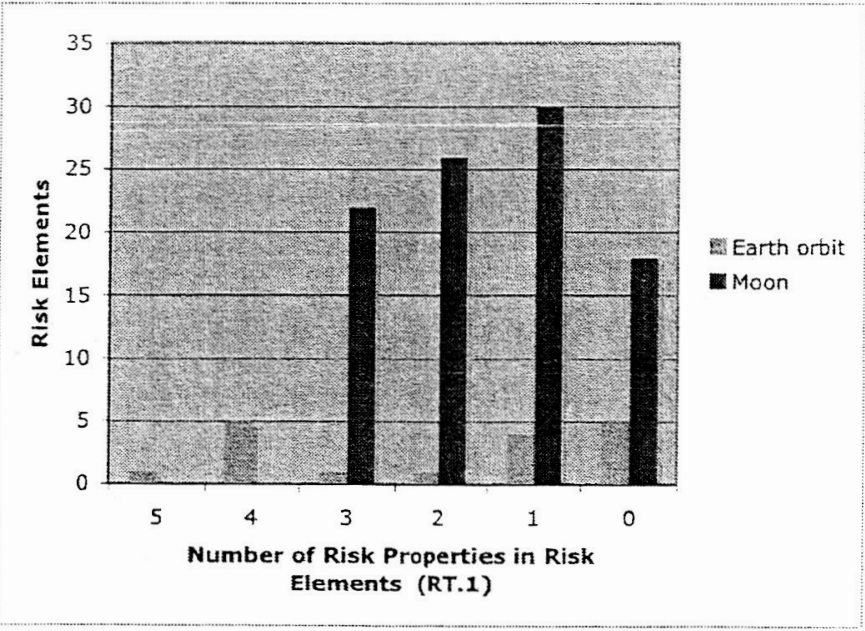

Figure 8: Relevance Theory Risk Element Analysis

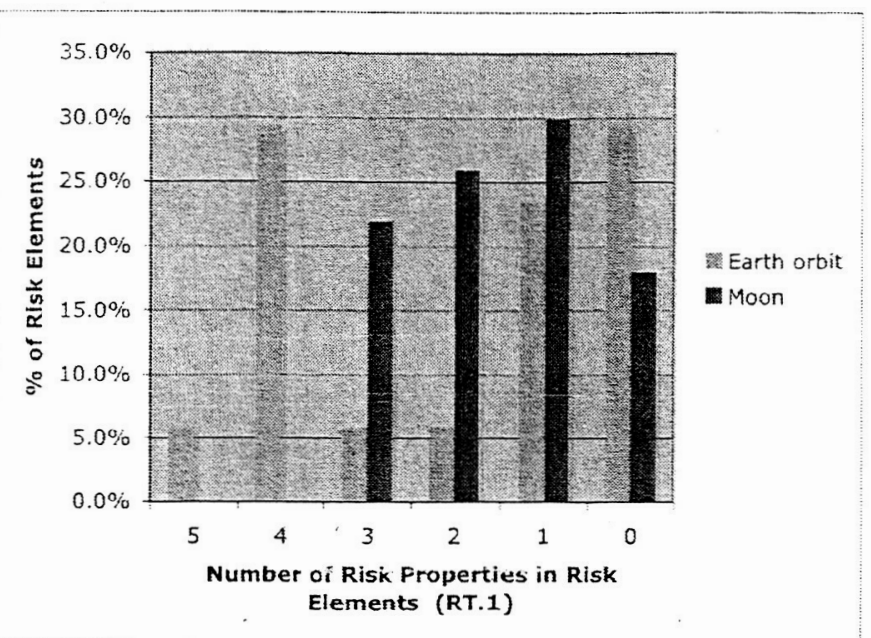

Figure 9: Relevance Theory Risk Element Analysis-

\section{Percentage}

Also, with respect to the second portion of the relevance theory, processing effort, it was determined that a risk element with at least 3 of the risk element properties satisfied the processing effort portion of the relevance theory. Figures 8 and 9 show that $20 \%$ of the moon mission risk elements meet this criteria while $35 \%$ of the Earth orbit mission risk elements meet this requirements.

\subsection{Discussion of Analysis Results}

Of all the attributes for which there is data, the lack of failure mode identification is significant. In addition, the number of risk elements for which affected functionality was identified is low. It is very apparent that the content in the sample of risk statements analyzed is deficient in terms of the pragmatic principles of communication.

Overall, it is reasonable to expect that the consistency of risk elements can be improved through adoption of a risk element format that requires specifications for a reasonable set of attributes such as those used in this work. This is in contrast to present conditions where the results clearly show the potential for greater clarity in documenting risks. Enforcement or other regulation of Team adherence to these types of attributes seems necessary for improvement. However, the authors recognize that modification of current practices may be difficult.

\subsection{Functional Template Results and Extensions}

The notion of a template is not new although the data presented in the appendix is a new contribution that helps illustrate the relation between functions and flows in the functional basis with high level systems used in space missions. Given the relatively low evidence of function and other references from the risk data analyzed in this work, these templates are suggestive of potential avenues to improve not only the reference of function, but inclusion of all five risk element attributes during risk elicitation, exploration, and documentation. The following provides a sketch of preliminary ideas regarding how this might occur. 


\subsubsection{Basic Concept}

Given the results of this work that indicate a need for increasing the reference and consideration of risk element properties, a central goal for developing tools such as RAP, is to facilitate user awareness of these five risk attributes. Without specifying details of a particular implementation or user interface, one potential use and extension of the functional templates as shown in the Appendix is a concept of a document similar to the templates. This concept presented next is better described as a worksheet rather than a template.

Upon developing the templates, it became apparent that arranging a matrix with function rows and system columns as show in the appendix is a convenient layout for describing the functions and flows associated with physical systems. It follows from this layout that such an arrangement can be redesigned to explicitly include all five risk attributes. Figure 9 illustrates this concept.

\begin{tabular}{|c|c|c|c|c|c|c|c|}
\hline \multicolumn{2}{|c|}{ Function } & \multicolumn{6}{|c|}{ System of Interest } \\
\hline Primary & Secondary & Flow & P & N & FM & FS & Risk \\
\hline \multirow{2}{*}{ Branch } & Separate & & & & & & \\
\hline & Distribute & & & & & & \\
\hline \multirow{4}{*}{ Channel } & Import & 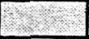 & -7 & 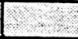 & $\square$ & 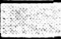 & \\
\hline & Export & 2 & 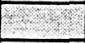 & 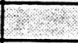 & 俩 & D & \\
\hline & \begin{tabular}{|l|} 
Transfer \\
\end{tabular} & 5 & ए & 8 & 唯 & 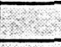 & - \\
\hline & Guide & 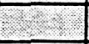 & 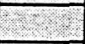 & 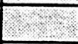 & 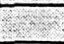 & 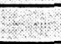 & \\
\hline \multirow{2}{*}{ Connect } & Couple & & & & & & \\
\hline & Mix & & & & & & \\
\hline \multirow{4}{*}{$\begin{array}{l}\text { Control } \\
\text { Magnitude }\end{array}$} & Actuate & & 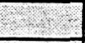 & 5 & 5 & ב & \\
\hline & \begin{tabular}{|l} 
Regulate \\
\end{tabular} & -2 & $\square$ & 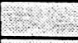 & 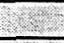 & 8 & \\
\hline & Change & 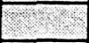 & $\square$ & 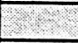 & 5 & 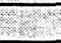 & \\
\hline & \begin{tabular}{|l|} 
Stop \\
\end{tabular} & 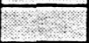 & 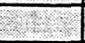 & $=$ & 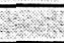 & $x^{2}$ & 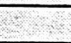 \\
\hline Convert & Convert & & & & & & \\
\hline \multirow{2}{*}{ Provision } & Store & 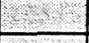 & $=$ & $=$ & 들 & 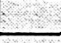 & \\
\hline & Supply & 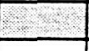 & 5 & 5 & s. & - & 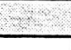 \\
\hline \multirow{3}{*}{ Signal } & Sense & & & & & & \\
\hline & Indicate & & & & & & \\
\hline & Process & & & & & & \\
\hline \multirow{2}{*}{ Support } & Stabilize & - & - & 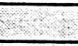 & 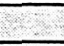 & 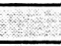 & 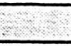 \\
\hline & Secure & & & & & & 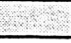 \\
\hline
\end{tabular}

\section{Figure 9: Function Based Risk Worksheet}

This concept in Figure 9 is a snapshot of how the five risk attributes can be accounted for. As shown, the design parameter $(D)$ attribute is represented by the rows of functions. With this layout, a system of interest can be documented in terms of its functionality, performance parameter $(P)$, noise parameter $(N)$, failure mode $(F M)$, failure scenario $(F S)$, and risk title or description $(R)$.

\subsubsection{Features and Scenarios of Usage}

Many alternative levels of sophistication are conceivable with this worksheet concept. A simple example is direct use of a layout like Figure 9 in a spreadsheet where a separate document is used for each system of interest. A more elaborate and advanced worksheet concept is an interactive spreadsheet, web applet or standalone application with underlying functionality for advanced features (searching, navigating, and reusing data from other sources). Example features might include the ability to navigate within hierarchies of physical systems, which is the case with the repository based FunctionFailure Design tool (FFDt) under joint development between UMR and NASA-Ames Research Center. Another example of other features includes linking between this Risk Worksheet and other applications such as Work Breakdown Structures (WBS), the RAP tool, and repository tools like the FFDt in order to support informed searches based on an appropriate blend of archived, perhaps quantitative, risk and function data with specific parameters relevant to the mission design at hand. For instance, performance parameters relevant to the mission are found in abundance in the WBS (eg. mass budget, etc.), which is continuously updated during Team $X$ sessions. Integrating a risk worksheet concept with other tools such as the WBS therefore seems logical in order to reuse data.

Finally, outlines of two usage scenarios are considered in order to illustrate how the function based risk worksheet concept offers potential advantages over the current process of dealing with risk. An assumption is that users are either the Team X member dedicated to risk issues (ie. the "Risk" chair) or potentially other Team X members as well depending on the degree of overhead necessary to perform the task.

In the simple scenario of implementing the worksheet in a spreadsheet manually for each system, the user can reference the functional templates in order to first identify flows associated with a given system. These flows can be directly used to aid in identifying $(P)$ since these performance parameters are often measures of flow variables. A set of $(N)$ can be generated because noise parameters are often implied if the objective / desired parameter $(P)$ is established. This is analogous to playing devils advocate when finding the parameters $(N)$ that will disturb system performance $(P)$. Given this context of function, flow, performance parameter, noise parameter, the user is primed for generating relevant failure modes, failure scenarios with the intent of ultimately collapsing these factors into a statement of risk in terms of likelihood and consequence.

An advanced scenario of implementing the worksheet involves the same overall process as the simple case except that enhanced functionality of the worksheet tool facilitates greater user flexibility in terms of their task process and greater support by reusing data from other sources. Here the user may begin with navigating to, or creating a system of interest through a browse feature. The user has an option of displaying parameters that are currently active from other tools such as the WBS. Based on these cues as well as ongoing discourse in the design room, the user gradually populates the worksheet, perhaps multiple worksheets at various system levels concurrently as information becomes more available and more concrete. All the while, the worksheet tool prompts the user, allows searches, or otherwise provides data from archived designs that is relevant to the current design. The final result of a set of risks in terms of likelihood and failure is directly transferred to the RAP tool.

\subsubsection{Corrective Actions for Addressing Risk}

These features and scenarios are suggestive of a significantly improved environment for eliciting, exploring, and 
documenting risk. Development of these concepts is an outcome of our improved understanding of how risk is addressed, based on the analysis described in section 4 . Specifically, our results demonstrate deficiencies in the content of risk elements in terms of the principles from pragmatics. The use of functional templates, the function based risk worksheet concept, and the processes described in the above scenarios are our proposed solution for taking corrective actions in order to improve how risk is addressed currently in Team $\mathrm{X}$ sessions. While the advanced tools outlined above require development, the simple case as described is deployable using the results presented here. Specifically, interested users can simply use Figure 9 as a starting point for their spreadsheets and implement the process described in the first scenario of section 5.5.2.

\subsection{CONCLUSIONS AND FUTURE WORK}

This paper focused on how designers communicate risks, and particularly how function is addressed in the risk elements. The risk information from a design team conducting an early stage design for space missions was decomposed into a set of key attributes, which are then used to analyze the risk information. Three approaches from the pragmatics sub-field of linguistics: i) Gricean, ii) Relevance Theory, and Functional Analysis provided insight of how designers communicate risk information with respect to certain metrics from these three perspectives. The results indicate that it is necessary to have all 5 attributes to satisfy gricean, which has the most stringent criteria.

This insight into how designers address function in risk elements leads to the overall conclusion that users account for all five risk element attributes. A practical means for taking this approach is by incorporating functional templates. These templates relate physical systems generally used in space missions with functions from the functional basis. In addition, the function based risk worksheet, which is a direct extension of the functional templates should assist designers in effectively eliciting, exploring, and documenting with risk with respect to the standards of the three linguistic principles.

The reliance on expert opinion to begin a process of establishing risks can hinder risk analysis since the setting of design team such as Team $\mathrm{X}$ tends to be chaotic. Therefore, a tool that presents a preliminary set of mission risks directly to the dedicated risk team member or to other members is useful to the design team by reducing the initial dependence of the risk chair on the other design team members. Future work should investigate the development and efficacy of advanced tool features described in section 5.5.2.

\section{REFERENCES}

Mark, G., "Extreme Collaboration," Communications of the $A C M, 45(6)$ : June 2002.
Meshkat, Cornford, S., and Moran, T., "Risk Based Decision Tool for Space Exploration Missions", American Institute of Aeronautics and Astronautics space Conference and Exhibition, AIAA 2003-6377.

Feather, M., and Cornford, S., "Quantitative Risk-Based Requirements Reasoning", Requirements Engineering Journal [in press].

Hirtz, J., Stone, R., McAdams, D., Szykman, S., and Wood, K., 2002, "A Functional Basis for Engineering Design: Reconciling and Evolving Previous Efforts", Research in Engineering Design 13(2): 65-82.

Tumer, I., Stone, R., and Bell, D., "Requirements for a Failure Mode Taxonomy for use in Conceptual Design", Proceedings of the International Conference on Engineering Design, ICED, Stockholm, 2003, paper 1612.

Uder, S., Stone, R., and Tumer, I., "Failure Analysis in Subsystem Design for Space Missions", Design Engineering Technical Donference DETC, Salt Lake City, UTAH, 2004, DTM-57338.

Tumer, I., Stone, R., "Mapping Function to Failure Mode During Component Development", Research in Engineering Design 14(1): 25-33

Stone, R., Tumer, I., Van Wie, M., "The Function Failure Design Method”, Journal of Mechanical Design [in press].

Bohm, M., and Stone, R., "Product Design Support: Exploring a Design Repository System", ASME International Mechanical Engineering Congress IMECE 2004-61746.

Wilson, R. and Keil, F., The MIT Encyclopedia of the Cognitive Sciences, A Bradford Book, The MIT Press, Cambridge, Mass, 1999.

Barsalou, L.W., Cognitive Psychology: An overview for Cognitive Scientists, Lawrence Erlbaum Associates, Inc., 1992.

Ward, Horn, Handbook of Pragmatics, Oxford: Blackwell, pp. $607-632$.

National Institute of Standards and Technology, 1993, Integration Definition for Functional Modeling (IDEFO). 


\section{Appendix: Functional Templates}

\begin{tabular}{|c|c|c|}
\hline Primary & Secondary & Notation \\
\hline \multirow{6}{*}{ Material } & Human & $H M$ \\
\hline & Gas & GS \\
\hline & +2 & LQ \\
\hline & Solid & SD \\
\hline & Plasma & $\mathrm{PL}$ \\
\hline & Mixture & $M X$ \\
\hline \multirow{2}{*}{ Signal } & Status & SS \\
\hline & Control & CS \\
\hline \multirow{12}{*}{ Energy } & Human & $\mathrm{HE}$ \\
\hline & Acoustic & $A E$ \\
\hline & Biological & -5 \\
\hline & Chemical & $C E$ \\
\hline & Electrical & EE \\
\hline & Electromagnetic & $E M$ \\
\hline & Hydraulic & $\mathrm{HD}$ \\
\hline & Magnetic & MG \\
\hline & Mechanical & $\mathrm{ME}$ \\
\hline & Pneumatic & $\mathrm{PE}$ \\
\hline & Radioactive/Nuclear & NK \\
\hline & Thermal & TH \\
\hline
\end{tabular}

Ground Systems Functional Template

\begin{tabular}{|c|c|c|c|c|c|}
\hline \multicolumn{2}{|c|}{ Function } & \multicolumn{4}{|c|}{ Ground Systems } \\
\hline Primary & Secondary & Power & Antenna & $\begin{array}{l}\text { Computer } \\
\text { facilities }\end{array}$ & $\begin{array}{l}\text { Control } \\
\text { center }\end{array}$ \\
\hline \multirow{2}{*}{ Branch } & Separate & EE & & $\mathrm{EE}, \mathrm{CS}$ & CS \\
\hline & Distribute & $\mathrm{EE}$ & & EE,CS & CS \\
\hline \multirow{4}{*}{ Chaninal } & Import & EM & EM & $E E, C S$ & cs \\
\hline & Export & $\mathrm{EE}$ & EM & EE,CS & CS \\
\hline & Transfer & $\mathrm{EE}$ & 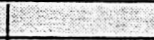 & CS & Cs \\
\hline & Guide & 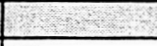 & 2 & 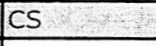 & - \\
\hline \multirow{2}{*}{ Connect } & Couple & $E E$ & & CS & CS \\
\hline & Mix & $\mathrm{EE}$ & & CS & $\mathrm{CS}$ \\
\hline \multirow{4}{*}{$\begin{array}{l}\text { Control } \\
\text { Magnitude }\end{array}$} & Actuate & EE & 5 & CS & 8 \\
\hline & Regulate & $\mathrm{EE}$ & 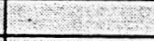 & CS & 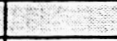 \\
\hline & Change & EE & 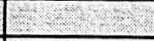 & CS & +2 \\
\hline & Stop & EE & 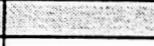 & CS & \\
\hline Convert & Convert & EM/EE & $\begin{array}{l}\text { EM/CS, } \\
\text { EE/EM }\end{array}$ & EE/CS & $\mathrm{HE} / \mathrm{CS}$ \\
\hline \multirow{2}{*}{ Provision } & Store & $\mathrm{NK}, \mathrm{EE}$ & $2=$ & $\mathrm{CS}$ & 5 \\
\hline & Supply & $E E$ & 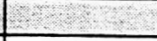 & CS & + \\
\hline \multirow{3}{*}{ Signal } & Sense & SS & $E M, C S$ & $\mathrm{CS}, \mathrm{SS}$ & CS \\
\hline & Indicate & SS & $E M, C S$ & CS,SS & CS \\
\hline & Process & & & CS & CS \\
\hline \multirow{2}{*}{ Support } & Stabilize & 5 & 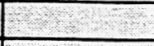 & & \\
\hline & Secure & 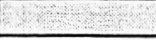 & +2 & & \\
\hline
\end{tabular}


Launch Vehicle Functional Template

\begin{tabular}{|c|c|c|c|c|c|c|c|c|}
\hline \multicolumn{2}{|c|}{ Function } & \multicolumn{7}{|c|}{ Launch Vehicle } \\
\hline Primary & Secondary & Power & $\begin{array}{l}\text { Computer } \\
\text { Hardware }\end{array}$ & Structure & Actuators & Shielding & Thermal & Propulsion \\
\hline \multirow{2}{*}{ Branch } & Separate & $\mathrm{EE}$ & $\mathrm{EE}, \mathrm{CS}$ & $\mathrm{ME}$ & & & & \\
\hline & Distribute & $\mathrm{EE}$ & $\mathrm{EE}, \mathrm{CS}$ & ME & & & & \\
\hline \multirow{4}{*}{ Channel } & Import & EM & $\mathrm{EE}, \mathrm{CS}$ & $M E ; S D$ & $\mathrm{EE}, \mathrm{SD}$ & & $\begin{array}{r}.21 \\
\end{array}$ & ME, GS \\
\hline & Export & EE & $\mathrm{EE}_{,} \mathrm{CS}$ & $\mathrm{ME}, \mathrm{SD}$ & $\mathrm{ME}, \mathrm{SD}$ & & & ME, GS \\
\hline & Transfer & $E E$ & CS & ME & 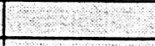 & + & 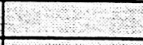 & $M E, G S$ \\
\hline & Guide & 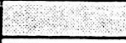 & CS & $M E$ & 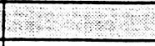 & 4 & $=$ & ME, GS \\
\hline \multirow{2}{*}{ Connect } & Couple & $\mathrm{EE}$ & CS & & SD & & & \\
\hline & Mix & $\mathrm{EE}$ & CS & & & & & \\
\hline \multirow{4}{*}{$\begin{array}{l}\text { Control } \\
\text { Magriitude }\end{array}$} & Actuate & EE & es & +2 & $\mathrm{ME}$ & & $\mathrm{TH}$ & $M E$ \\
\hline & Regulate & EE & $\mathrm{CS}$ & $M E, A E$ & 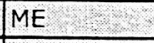 & 4 & $\mathrm{TH}$ & ME \\
\hline & Change & EE & CS & 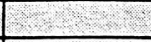 & $M E$ & & $\mathrm{TH}$ & $M \bar{E}$ \\
\hline & Stop & $E E$ & $\mathrm{CS}$ & 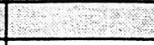 & $M E$ & SD & $\mathrm{TH}$ & ME \\
\hline Convert & Convert & EM/EE & $E E / C S$ & & $\begin{array}{l}E E / M E, \\
E E / H D \\
\end{array}$ & & $\mathrm{EE} / \mathrm{TH}$ & $\begin{array}{l}\text { CE/ME, } \\
\text { NK/ME }\end{array}$ \\
\hline \multirow{2}{*}{ Provision } & Store & $\mathrm{NK}, \mathrm{EE}$ & CS & 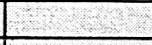 & 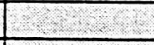 & & $\mathrm{TH}$ & $\mathrm{CE}, \mathrm{NK}$ \\
\hline & Supply & $\mathrm{EE}$ & CS & L & 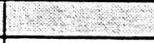 & - & $\mathrm{TH}$ & $x=$ \\
\hline \multirow{3}{*}{ Signal } & Sense & CS,SS & CS,SS & SS & CS,SS & & $C S, S S$ & CS \\
\hline & Indicate & SS & CS,SS & SS & CS,SS & & SS & SS \\
\hline & Process & & CS & & CS & & & \\
\hline \multirow{2}{*}{ Support } & Stabilize & $=5$ & & $M E, S D$ & $M E$ & & (2) & $\mathrm{ME}$ \\
\hline & Secure & 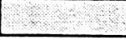 & & $M E, S D$ & ME & & & ME \\
\hline
\end{tabular}

\section{Spacecraft Functional Template}

\begin{tabular}{|c|c|c|c|c|c|c|c|c|c|}
\hline \multicolumn{2}{|c|}{\begin{tabular}{|l|} 
Function \\
\end{tabular}} & \multicolumn{8}{|c|}{ Spacecraft } \\
\hline Primary & Secondary & Power & Antenna & $\begin{array}{l}\text { Computer } \\
\text { Hardware }\end{array}$ & Structure & Actuators & Shielding & Thermal & Propulsion \\
\hline \multirow{2}{*}{ Branch } & Separate & $\mathrm{EE}$ & & $E E, C S$ & $M E$ & & & & \\
\hline & Distribute & $\mathrm{EE}$ & & $\mathrm{EE}, \mathrm{CS}$ & ME & & & & \\
\hline \multirow{4}{*}{ Channel } & Import & EM & EM & $\mathrm{EE}, \mathrm{CS}$ & $M E, S D$ & $\mathrm{EE}, \mathrm{SD}$ & 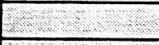 & +2 & ME, GS \\
\hline & Export & EE & EM & $\mathrm{EE}, \mathrm{CS}$ & $\mathrm{ME}, \mathrm{SD}$ & $\mathrm{ME}, \mathrm{SD}$ & 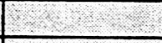 & + & $M E, G S$ \\
\hline & Transfer & EE & 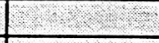 & CS & ME & $+2=0$ & \begin{tabular}{|l|c|}
-20 \\
\end{tabular} & 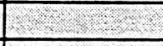 & ME, GS \\
\hline & Guide & +2 & . & CS & ME & 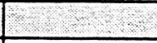 & 1.\$: & 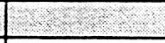 & ME, GS \\
\hline \multirow{2}{*}{ Connect } & Couple & $E E$ & & CS & & SD & & & \\
\hline & Mix & $E E$ & & CS & & & & & \\
\hline \multirow{4}{*}{$\begin{array}{l}\text { Control } \\
\text { Magnitude }\end{array}$} & Actuate & EE & 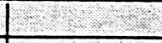 & CS & 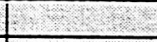 & $M E$ & -112: & TH & $\mathrm{ME}$ \\
\hline & Regulate & EE & 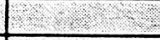 & CS & $M E, A E$ & $\mathrm{ME}$ & 2 & $\mathrm{TH}$ & $\mathrm{ME}$ \\
\hline & Change & $E E$ & 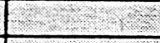 & CS & 2. & ME & ( & $\mathrm{TH}$ & ME \\
\hline & Stop & $\mathrm{EE}$ & 1.2. & CS & $4=$ & $\mathrm{ME}$ & SD & $\mathrm{TH}$ & ME \\
\hline Convert & Convert & EM/EE & $\begin{array}{l}\text { EM/CS, } \\
\mathrm{EE} / \mathrm{EM}\end{array}$ & $\mathrm{EE} / \mathrm{CS}$ & & $\begin{array}{l}\mathrm{EE} / \mathrm{ME}, \\
\mathrm{EE} / \mathrm{HD}\end{array}$ & & EE/TH & $\begin{array}{l}\text { CE/ME, } \\
\text { NK/ME }\end{array}$ \\
\hline \multirow{2}{*}{ Provision } & Store & NK,EE & $=9$ & CS & 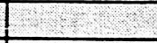 & . & 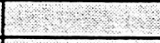 & $\mathrm{TH}$ & $C E, N K$ \\
\hline & Supply & EE & $=$ & $\mathrm{CS}$ & 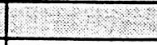 & D. & \begin{tabular}{|l|l} 
\\
\end{tabular} & $\mathrm{TH}$ & 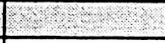 \\
\hline \multirow{3}{*}{ Signal } & Sense & CS,SS & EM,CS & CS,SS & SS & CS,SS & & CS,SS & $C S$ \\
\hline & Indicate & SS & EM,CS & $\mathrm{CS}, \mathrm{SS}$ & SS & CS,SS & & SS & SS \\
\hline & Process & & & CS & & CS & & & \\
\hline \multirow{2}{*}{ Support } & Stabilize & $\therefore$ & $M E$ & 5. & ME, SD & ME & 8 & 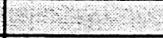 & ME \\
\hline & Secure & $\square$ & $\mathrm{ME}$ & 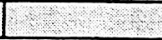 & $M E, S D$ & ME & 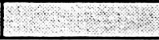 & 1. & ME \\
\hline
\end{tabular}


Payload

\begin{tabular}{|c|c|c|c|c|c|c|c|c|c|c|}
\hline \multicolumn{2}{|c|}{ Function } & \multicolumn{9}{|c|}{ Payload } \\
\hline Primary & Secondary & Power & Antenna & $\begin{array}{l}\text { Computer } \\
\text { Hardware }\end{array}$ & Structure & Actuators & Shielding & Thermal & Propulsion & Science \\
\hline \multirow{2}{*}{ Branch } & Separate & $E E$ & & EE,CS & ME & & & & & \\
\hline & Distribute & EE & & EE, CS & ME & & & & & \\
\hline \multirow{4}{*}{ Channel } & Import & $E M$ & $E M$ & EE, CS & $M E, S D$ & EE, SD & & & ME, GS & EE \\
\hline & Export & EE & EM & EE,CS & ME, SD & $M E, S D$ & & & ME, GS & SS,CS \\
\hline & Transfer & $\mathrm{EE}$ & & CS & ME & SD & & & $M E, G S$ & $\mathrm{SD}, \mathrm{GS}, \mathrm{MX}$ \\
\hline & Guide & . & +2 & $\mathrm{CS}$ & ME & SD & +2 & & ME, GS & SD, GS, MX \\
\hline \multirow{2}{*}{ Connect } & Couple & EE & & CS & & SD & & & & $\mathrm{SD}, \mathrm{GS}, \mathrm{MX}$ \\
\hline & Mix & EE & & $\mathrm{CS}$ & & & & & & SD, GS \\
\hline \multirow{3}{*}{$\begin{array}{l}\text { Control } \\
\text { Magnitude }\end{array}$} & Actuate & EE & & CS & & ME & & TH & & $M E, C E, E M$ \\
\hline & Regulate & EE & 80 & CS & $M E, A E$ & ME & & $\mathrm{TH}$ & ME & $M E, C E, E M$ \\
\hline & Stop & $E E$ & + & CS & & MiE & SO & in & & $\mathrm{MIE}, \mathrm{CE}, \mathrm{EM}$ \\
\hline Convert & Convert & EM/EE & $\begin{array}{l}E M / C S, \\
E E / E M\end{array}$ & EE/CS & & $\begin{array}{l}E E / M E, \\
E E / H D\end{array}$ & & EE/TH & $\begin{array}{l}\text { CE/ME, } \\
\text { NK/ME }\end{array}$ & EE, EM \\
\hline \multirow{2}{*}{ Provision } & Store & NK, EE & $4 \times$ & $\mathrm{CS}$ & 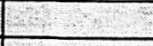 & . & 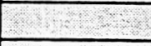 & $\mathrm{TH}$ & $C E, N K$ & $\mathrm{SD}, \mathrm{GX}, \mathrm{MX}$ \\
\hline & Supply & $\mathrm{EE}$ & 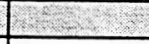 & CS & 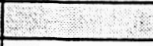 & 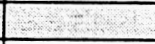 & . & TH & : & 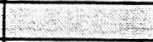 \\
\hline \multirow{3}{*}{ Signal } & Sense & CS,SS & EM,CS & CS,SS & SS & CS,SS & & CS, SS & CS & SS, CS \\
\hline & Indicate & 55 & $E M, C S$ & CS,SS & SS & CS,SS & & SS & SS & SS,CS \\
\hline & Process & & & CS & & CS & & 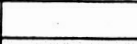 & & SS, CS \\
\hline \multirow{2}{*}{ Support } & Stabilize & 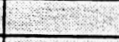 & $\mathrm{ME}$ & : & ME,SD & ME & & & ME & SD \\
\hline & Secure & . & $M E$ & 1 . ni: & $\mathrm{ME}, \mathrm{SD}$ & ME & & & ME & $S D$ \\
\hline
\end{tabular}

